\title{
Understanding veterinary quackery in Uganda
}

\section{Opinion}

Uganda is a small country located in the East African region whose economic backbone is agriculture. In Uganda it takes three years and five years to graduate a para-vet and veterinarian, respectively. Upon qualification one is required by law to register with the Uganda Veterinary Board (UVB) which maintains a register of all qualified vets in Uganda. One of the challenges faced by the animal population is the scarcity of veterinary health workers in different areas which has resulted into emergence of unqualified veterinary officers. ${ }^{1}$ Veterinary Quackery is defined as "Practice by unqualified individual as required by law to offer veterinary services in form of animal treatment, distribution of restricted animal drugs and impersonation as a veterinarian". ${ }^{2}$ This is a problem many clients (farm and companion animal owners) face in Uganda today. Unfortunately, because of the gap that has been created due to scarcity of qualified veterinary officers to animal owners in different areas of the country, this has given a golden opportunity to the proliferation of veterinary quacks who appeal to such growing demand of veterinary services. Quackery as a practice appeals to the emotions of animal owners and thus the professional bodies giving a deaf ear we may be empowering them something already happening in Uganda and Africa as a whole.

Today, modern health quacks have invested time and energy to develop such dishonest practices and claims to have special knowledge and skill in veterinary medicine thus turning out to be super salesmen. They have developed a skill of being quick problem solvers with instant solutions. At some point I was told that they pose to have a quick fix to some animal deadly animal problems with a magic drug. Farmers have always asked me how they can identify quacks. One thing I have come to notice about quacks is that they hardly leave records. This is typical of quacks; a trained animal health professional always leaves behind a documented record giving his tentative or confirmed diagnosis and the medications given. They do so because they know they are committing a legal offense, and they may not know what and how to write a medical report. ${ }^{3}$ Under this Umbrella I have met several dog trainers who pose as veterinarians based on experience and time they have spent in this field to the extent of undermining veterinarians before clients as people who don't know what to do. Unfortunately their game at times doesn't run for long until maybe they are challenged by a serious clinical problem. I always tell animal owners that quacks are equivalent to short cuts in life because of their services. They are cheap and seem more appealing to work for any cost a client can offer after all they never paid anywhere regarding money and time to be veterinarians. ${ }^{4}$ They have sought such unimaginable confidence to the extent of claiming to be demigods.

In 2018 in Kenya our neighboring country in the East a quack identified as Walter claimed that he was able to bring back to life the dead Northern White Rhino -Sudan attributing it to his genetic engineering knowledge. Quacks have executed a number of bizarre
Volume 8 Issue 4 - 2019

\author{
Nelson France Bukamba \\ Private Veterinary practitioner, Uganda
}

Correspondence: Nelson France Bukamba, Private Veterinary practitioner, Uganda, Africa, Tel +256704540808, Email bukambafrance@gmail.com

Received: June 18, 2019 | Published: July 04, 2019

operations with such confidence all in the name of performing miracles which has costed many farmers and animal owners. They have indeed violated the "golden rule" of "do for others what you want done for you" and thus becoming a barrier to proper animal health and increase in income to livestock producer. ${ }^{5}$ One way animal owners have been advised as able to identify a qualified veterinarian for their animals is the demand for the professional identity cards of anyone attending to their animals and watch out for individuals who claim to have quick fix to their problems because that's not part of our ethical conduct as veterinarians.

\section{Acknowledgments}

I would acknowledge Dr. Sylvia Nalubawa a lecture at Makerere University, school of veterinary medicine and animal resources for the guidance during my write up and survey of information.

\section{Conflicts of interest}

The author declares that there are no conflicts of interest.

\section{References}

1. Tygerberg LJK. Vets must sensitise public against quacks. New Vision. 2008.

2. Bones VC, Yeates JW. The emergence of veterinary oaths: Social, historical, and ethical considerations. Journal of Animal Ethics. 2012;2(1):20-42.

3. Achuka V. Here's How To Catch Veterinary Quacks Risking Your Animal's Life. Daily Nation. 2014.

4. K'Oloo TO, Ilukor J, Mockshell J, et al. Are government veterinary paraprofessionals serving the poor? The perceptions of smallholder livestock farmers in Western Kenya. Tropical animal health and production. 2015;47(1):243-245.

5. Chenais E, Boqvist S, Sternberg-Lewerin S, et al. Knowledge, attitudes and practices related to African swine fever within smallholder pig production in northern Uganda. Transboundary and emerging diseases. 2017;64(1):101-115. 